Gut, 1962, 3, 181

Methods and techniques

\title{
Telemetering from within the body using a pressure-sensitive radio pill
}

\author{
B. W. WATSON, B. ROSS, AND A. W. KAY \\ From the Regional Medical Physics Department and the University \\ Department of Surgery, Royal Infirmary, Sheffield
}

It has been an aim of the clinical physiologist to be able to measure continuously such physiological variables as pressure, temperature, and hydrogen ion concentration under conditions of minimal disturbance to the subject or his environment.

The development of miniature electronic components, such as the transistor, has made it possible to construct transducers and amplifiers within such a small space that studies can be undertaken in hitherto inaccessible parts of the human body. A radio transmitter with a total volume of approximately $2 \mathrm{cc}$. which can transmit information from the inside of the body was described in 1957 (Mackay and Jacobson, 1957). These devices have been further developed and they have been used mainly to investigate the gastrointestinal tract. Telemetering capsules ('radio pills') capable of recording pressure, temperature, and $p \mathrm{H}$ have been produced and a review of these devices is given elsewhere (Mackay, 1959, 1961; Jacobson, 1960; Wolff, 1961). They transmit a frequency modulated signal in the frequency range $300 \mathrm{Kc} / \mathrm{s}$ to $10 \mathrm{Mc} / \mathrm{s}$. The pressure pill modifications described in this paper enable the construction of a simple, reliable and inexpensive device.

\section{SPECIFICATION}

1 The device should be as small as possible and not greater than $3 \mathrm{~cm}$. long by $1 \mathrm{~cm}$. diameter.

2 The battery must be replaceable. Available pills in Great Britain permit of single studies only.

3 The transmissions should continue for not less than 50 hours.

4 The response to pressure should be linear.

5 It must possess a sensitivity which can be adjusted from $50 \mathrm{~cm}$. water to $300 \mathrm{~cm}$. water full-scale deflection on the recorder.

6 The temperature stability should be such that the pressure measured is accurate to $10 \%$ over the range of $95^{\circ} \mathrm{F}$. to $105^{\circ} \mathrm{F}$.
7 The frequency on which the pill transmits should be variable so that two or more pills can be used synchronously in one subject.

8 The characteristics of the diaphragm should not be affected by the body fluids encountered by the capsule.

9 The design should be flexible so that parameters other than pressure can be measured without necessitating major basic modifications of the capsule.

The pills described so far have fallen short of these ideal requirements in one or more respects.

All circuits use the variation in inductance. Pressure variations on a rubber or perspex diaphragm or a metal bellows cause movement of a ferrite core or disc which modifies an inductance in the circuit. Both rubber and perspex are affected by water and body fluids. To overcome this, silicone grease (Connell and Rowlands, 1960) or a silicone fluid seal is necessary between the diaphragm and the body fluids. Even when these precautions are taken, and a special rubber has been developed for this purpose (Jacobson, 1960), long-term changes still occur. The ferrite pot core (Rowlands and Wolff, 1960) seemed to offer the possibility of using a metal diaphragm.

\section{CONSTRUCTION}

The circuit used is the Clapp oscillator shown in Fig. 1. The inductance $(L)$ is wound on a small ferrite pot core and the magnetic circuit completed by a disc of ferrite. The inductance depends on the air gap between this disc and the core, variations in the gap causing a change in the inductance (L), and this in turn leads to a change in frequency of oscillations. The carrier frequency is in the band 300 to $500 \mathrm{Kc} / \mathrm{s}$ and the modulation caused by a positive pressure is such as to decrease the frequency by approximately $20 \mathrm{Kc} / \mathrm{s}$.

The components are wired into a perspex former and sealed into the perspex body before the diaphragm assembly is undertaken.

The mechanical layout is shown in Fig. 2. The body of the pill is machined from $\frac{3}{8}$ in. diameter perspex rod. The metal diaphragm is a silver-plated 1 thou. thick copper disc $7.5 \mathrm{~mm}$. in diameter. This rests on a shoulder machined into the perspex body. A brass spigot tapped 
Components

FIG. 1. Radio pill circuit.

$L_{1} 90$ turns of 47 s.w.g. (Pot core B 65501 $M 25 O L)$ (R. H. Cole Ltd.)

$L_{2} 300$ turns of 47 s.w.g.

$C_{1}$ and $C_{3} \quad 0.001$ micro-farad (Hunts Ltd.).

$C_{2} \quad 0.003$ micro-farad (Hunts Ltd.).

$R \quad 47 k$ (Fortiphone Ltd.).

$T$ 2N207(Philco).

B RM312 (Mallory Battery Ltd.).
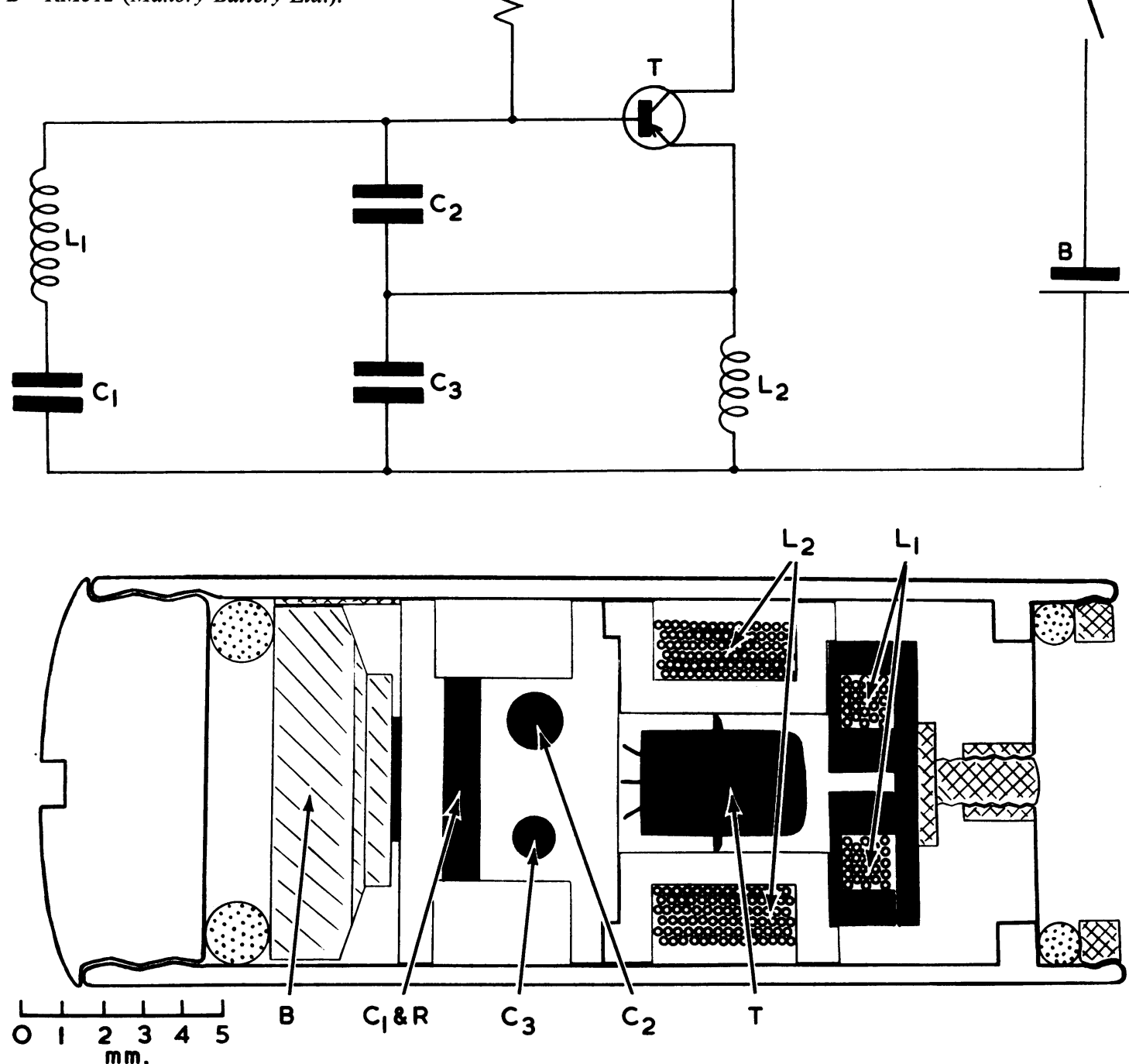

FIG. 2. Mechanical layout of the radio pill.

with a 14BA thread is attached with Araldite resin to the diaphragm. The ferrite disc is secured with Araldite to a brass disc machined on to the end of a 14BA screw, which is then fitted into the brass spigot. This assembly permits accurate adjustment of the gap in the pot core. It is essential to have the ferrite disc accurately aligned parallel to the pot core and this requires the disc to be ground flat after it is attached to the screw. A rubber ' $O$ ' seal and a brass pressure ring seal the pill from leaks at the diaphragm.

The battery end must be sealed from the diaphragm chamber and B.I.P. resins have been used to encapsulate 
the electronic components, so ensuring a rigid assembly and a good seal. If a slight leak still remains, silicone grease can be used in the battery end.

In preliminary work, adhesives were used to attach the

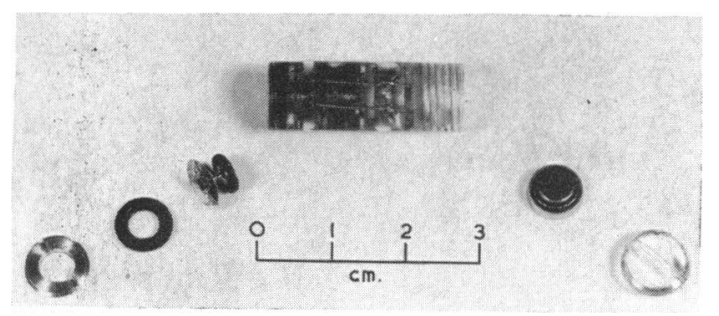

FIG. 3. The radio pill. metal diaphragm but this had three disadvantages: first, a good seal between metal and perspex was difficult to obtain; secondly, spreading of the adhesive affected the properties of the disc; thirdly, it is necessary to be able to replace the diaphragm assembly quickly because damage can occur during recovery from the body or during the cleaning process which is necessary before the capsule is used in another clinical experiment. The completed pill together with the diaphragm assembly is shown in Fig. 3.

\section{PRESSURE CHARACTERISTIC}

Typical pressure curves are shown in Fig. 4. The maximum sensitivity is $50 \mathrm{~cm}$. $\mathrm{H}_{2} \mathrm{O}$. Higher sensitivities can be achieved but stability considerations make it impractical. The error due to non-linearity is less than $5 \%$ of fullscale value. If it is required to measure pressures greater than $150 \mathrm{~cm} . \mathrm{H}_{2} \mathrm{O}$ it is necessary to increase the thickness of the diaphragm in order to retain linearity.

\section{TEMPERATURE CHARACTERISTIC}

Considerable care is needed in order to get a pill which is stable in a changing temperature environment. A temperaturesensitive reactance is not used in the present circuit. Fortunately the change in frequency due to component variations, particularly in the transistor, causes the frequency to decrease whereas the air which is contained within the pill expands with increase in temperature causing the frequency to increase; by adjusting the gap in the pot core it is usually possible to balance out the two effects. The differing temperature curves which are obtained from a typical pill by increasing the sensitivity to pressure are shown in Fig. 5; the enclosed air has more effect and competes with the temperature drifts in components. It must be stressed that because of the inherent variations in the temperature coefficients of the components extreme care must be taken to prepare each pill individually.

It is possible after the above adjustments have been made, to have pills which are accurate to $3 \%$ over the range $95^{\circ}$ to $105^{\circ} \mathrm{F}$. In general, the average pills are accurate to within $10 \%$ over $95^{\circ} \mathrm{F}$. and $101^{\circ} \mathrm{F}$., after arranging the 


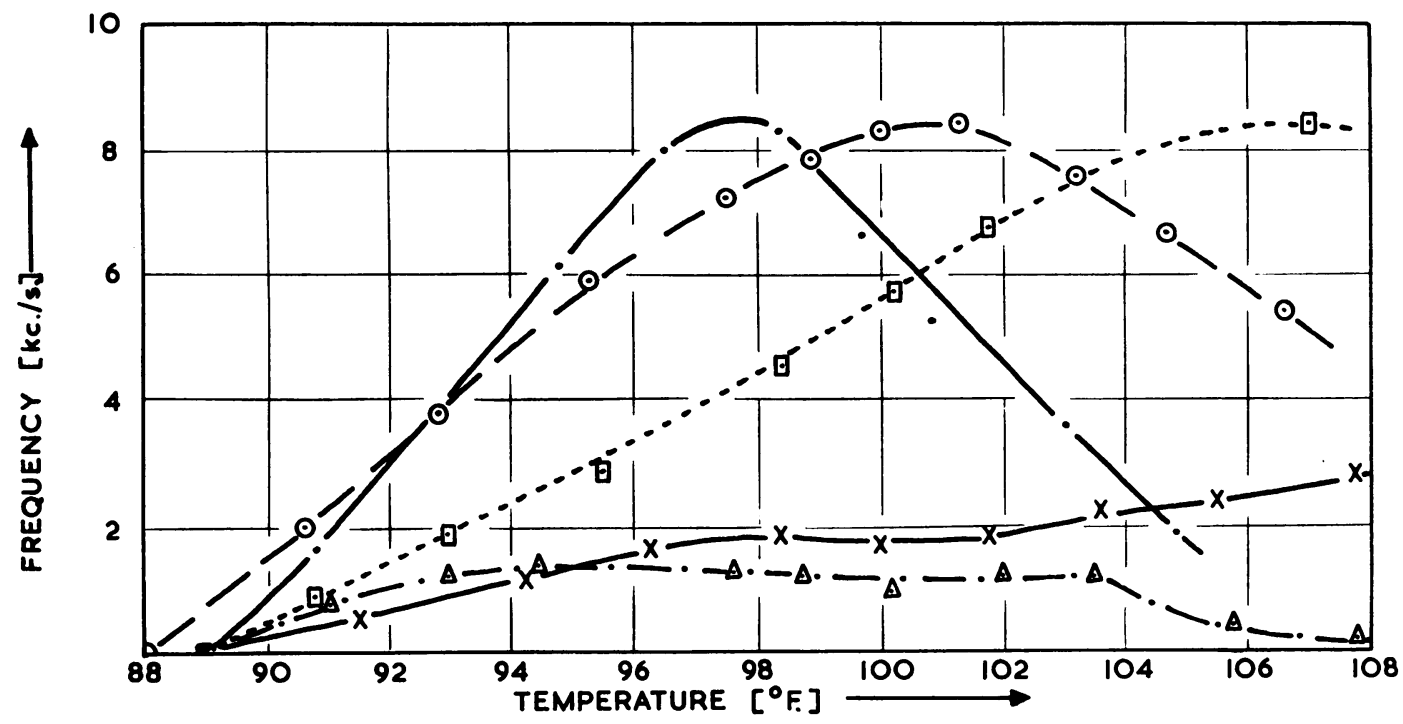

FIG. 5. Temperature characteristics.

$$
\begin{array}{llll}
\text { Sensitivities } & \text { Pill MI } & -\times-0.66 \mathrm{kc} / \mathrm{s} / \mathrm{cm} . \mathrm{Hg} & -\bigcirc-1.26 \mathrm{kc} / \mathrm{s} / \mathrm{cm} . \mathrm{Hg} \\
& & -.-1.66 \mathrm{kc} / \mathrm{s} / \mathrm{cm} . \mathrm{Hg} & -\square-1.09 \mathrm{kc} / \mathrm{s} / \mathrm{cm} . \mathrm{Hg} \\
& & \text { Pill M4 }-\triangle-2.0 \mathrm{kc} / \mathrm{s} / \mathrm{cm} . \mathrm{Hg} &
\end{array}
$$

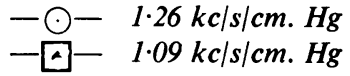

turning point of the curve to be at $98^{\circ} \mathrm{F}$. as shown in Fig. 4. Normally the calibrations are done at $98^{\circ} \mathrm{F}$. and the percentage accuracy quoted above is based on this figure.

6

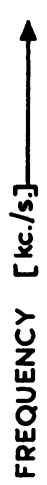

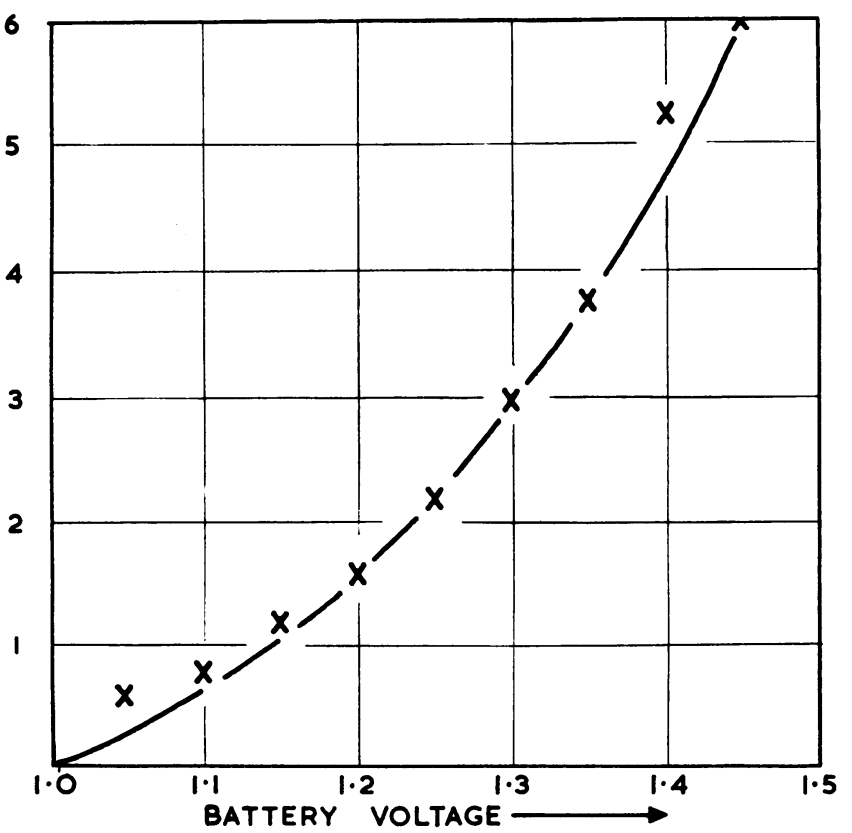

FIG. 6. Frequency drift with change in battery voltage.
STABILITY

If the frequency of the transmitter changes over the life of the pill, the base line of pressure measurements will drift. This is inconvenient for long-term studies of pressure changes and would preclude reliable analysis. Furthermore, frequency changes must be prevented if absolute pressure measurements are required. This effect may be due to a change in the circuit condition caused by variation in the battery voltage or to deterioration in the mechanical properties of the diaphragm.

The Mallory cell type RM312 is used to power the pill. The cell has a stable voltage curve as the current is drained from it and regulation is within $0.5 \%$.

The voltage drops quickly from 1.35 volts to 1.32 volts over the first 30 minutes and then remains within the quoted regulation. The variation in frequency with battery voltage is shown in Fig. 6. It will be seen that, from battery changes alone, the pill is stable within the above period assuming that 30 minutes is allowed for the pill to stabilize after refuelling. The drift in base line during recordings from ingested pills corresponds to a change in the carrier frequency of less than $3 \%$; this figure is inclusive of receiver drift. 


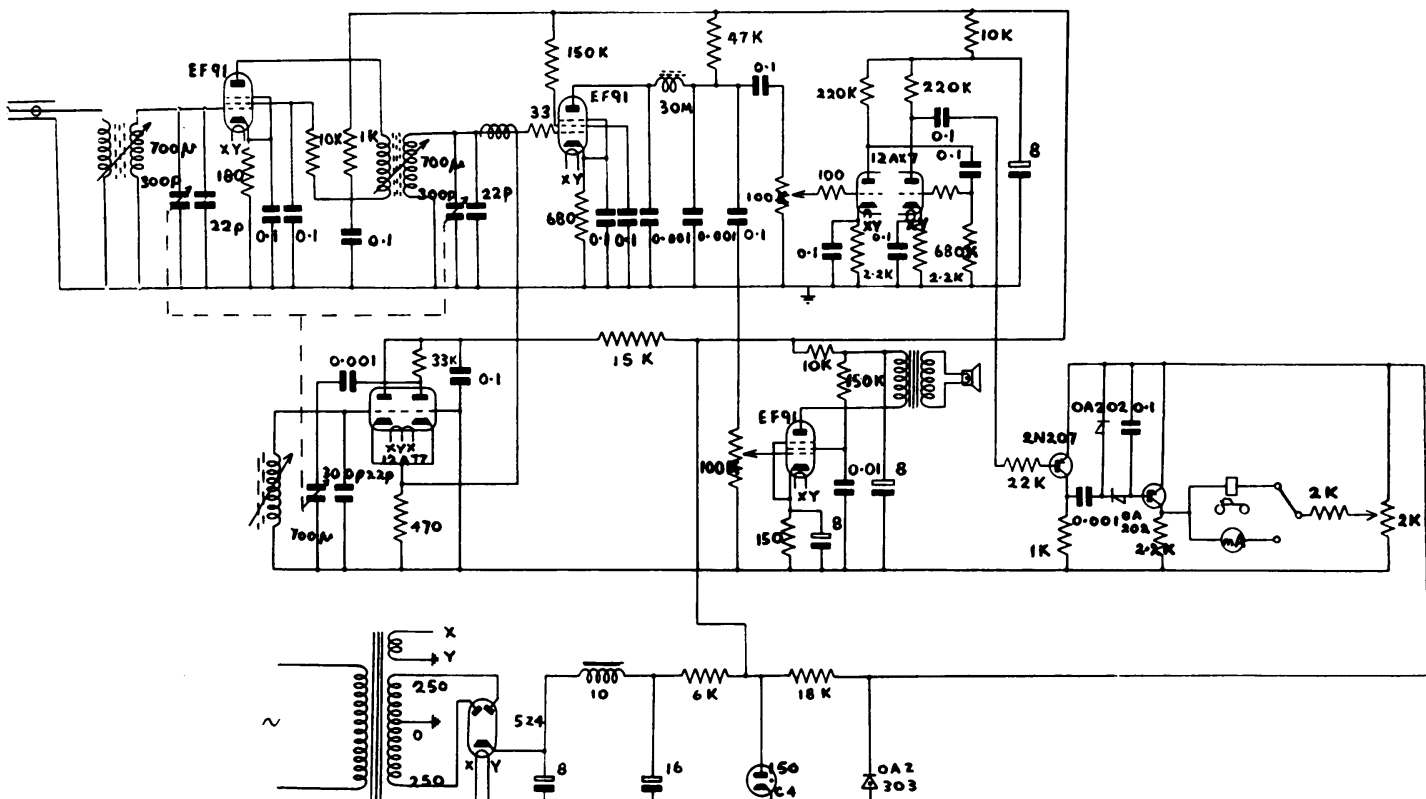

FIG. 7. Radio receiver cireuit:

On pills tested after recovery and refuelling, the pressure calibration has been found to be the same.

\section{RECEIVING TECHNIQUES}

The radio receiver is of a simple type (Fig. 7). This receiver is inexpensive and, provided local interference is not a problem, is also reliable. The radio signal is picked up on a small ferrite aerial, amplified, and then demodulated by mixing with a local oscillator signal of the same frequency as that of the pill. The resulting audio signal is then amplified and counted on the rate-

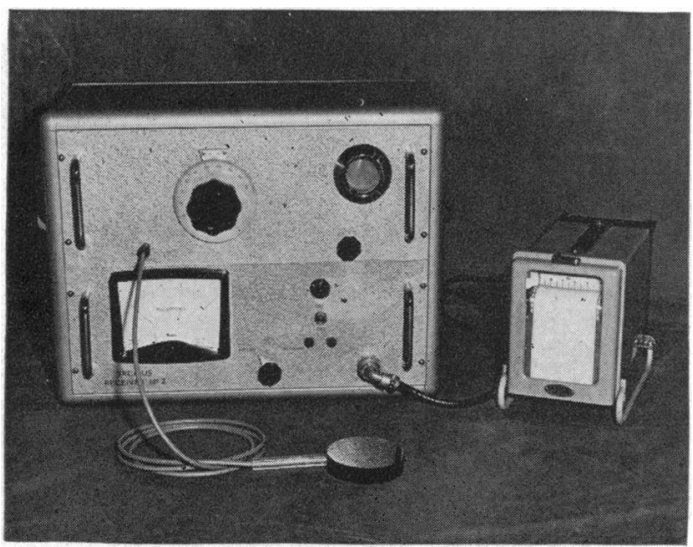

FIG. 8. Radio receiver and recorder. meter. The ratemeter converts the 0 to $20 \mathrm{Kc} / \mathrm{s}$ audio signal into a 0 to $1 \mathrm{~m}$.amp current which is recorded on a pen recorder. The receiver drifts less than $\pm 1 \mathrm{Kc} / \mathrm{s}$ in 24 hours after an initial warm-up period of 30 minutes. The circuit will respond to 10 microvolts of signal at the input and the ratemeter is independent of signal strength from 10 microvolts to 100 millivolts. With this receiver it is possible to lose the signal if the pill is orientated in a critical position. In practice this happens rarely and if a clamp circuit holds the ratemeter until the signal returns the record is not seriously affected. The signal level can also be recorded but in our initial studies this has not been necessary.

The clinical readings are made by adjusting the base line to $\mathbf{0 . 2}$ m.amps on the recording milliameter. If the signal is lost during the recording the needle returns to zero on the paper. The complete instrument together with the recorder is shown in Fig. 8.

To date our clinical studies have been limited to the life of the pill ( 80 hours). The receiver described by Jacobson (1960) would seem to be the one of choice for studies over periods greater than three days.

\section{CLINICAL APPLICATION}

The telemetering capsule and the radio receiver described above have been used to study the effect of various abdominal operations on gastro-intestinal motility in man. The capsule, previously sterilized by immersion in $0.5 \%$ solution of hibitane in spirit for four hours, is inserted at the duodeno-jejunal flexure. Thus, without inconvenience to the patient, the pill can be monitored continuously from the end of the operation until the 
return of typical type 3 pressure waves is observed on the permanent record.

The duration of small bowel paralysis after various operations, including resection of the vagus nerves to the stomach, has been determined and is soon to be reported. Changes in gastric motility are recorded by suturing a capsule to the gastric mucosa. The results of these studies have an important bearing on the postoperative management of patients undergoing gastrointestinal surgery.

In some patients, recordings have been made simultaneously from the stomach and small intestine. This has been rendered feasible by the flexibility of the design of our telemetering device.

In clinical experiments on the urinary bladder, the stability of our pill has permitted measurement of absolute pressures during postural changes, and recordings of intravesical pressure during normal micturition.

\section{CONCLUSIONS}

The pills described above have been shown capable of recording pressure changes over the period of the battery life ( 80 hours).

The drifts in the recorder base line are small but these could be reduced considerably by improving the receiver. These improvements would seem to be essential if the radio pill is to be used as a diagnostic technique in gastroenterology.

The information collected over a period of three days is considerable, and some method of electrical recording such as magnetic tape is necessary in order that electronic analysis can be made. Collecting information from pills sutured in known parts of the intestine will aid this analysis.

From our experience it is clear that economic considerations alone demand that the device be recoverable. Most clinical research projects require a large number of experiments and, furthermore, it is difficult to envisage adequate testing of a sealed device without loss of a large proportion of the useful life.
In future developments a smaller device would seem to offer possibilities for studies in children but it is difficult to see how the present design could be reduced significantly.

An externally energized pill would offer advantages if recordings over many months are envisaged and if it enabled the size to be reduced substantially. Recordings from dogs have been made by Jacobson and Lindberg (1960) over a period of three weeks and, using a larger battery, for as long as three months.

We wish to express our thanks to Miss D. Wemm, Mr. H. Wood, and Mr. W. Dyson for technical assistance. Our thanks are also due to Mr. H. Wolff, of the Medical Research Council Bioengineering Laboratory, who has been responsible for much of the early developmental work on radio-telemetering in this country, for many helpful discussions. Together with Solartron Electronics Ltd., Mr. Wolff developed the perspex diaphragm pill, experience with which has led to the modifications described. This work has been supported by the research funds of the United Sheffield Hospitals and the Sheffield Regional Hospital Board.

\section{REFERENCES}

Connell, A. M., and Rowlands, E. N. (1960). Wireless telemetering from the digestive tract. Gut, 1, 266-272.

Jacobson, B. (1960). Development and use of endoradiosonde techniques. Progressive Report, Karolinska Institutet, Department of Medical Electronics.

$\longrightarrow$, and Lindberg, B. (1960). F.M. receiving system for endoradiosonde techniques. I.R.E. Transactions on Medical Electronics, October 1960, pp. 334-339.

Mackay, R. S. (1959). Radio telemetering from within the human body. I.R.E. Transactions on Medical Electronics, June 1959, pp. 100-105.

(1961). Radio telemetering from within the body. Science, 134, 1196-1202.

- and Jacobson, B. (1957). Endoradiosonde. Nature (Lond.) 179, 1239-1240.

Rowlands, E. N., and Wolff, H. S. (1960). The radio pill. Telemetering from the digestive tract. British Communications and Electronics, 7, 598-601.

Wolf, H. S. (1961). 'The Radio Pill'. New Scientist, 12, 419-421. 